\title{
El medio es el mensaje. Génesis y desarrollo de la imagen sobre la plancha de metal
}

The Media is the Message. Genesis and Development of the Picture on Metal Plate

Hay dos maneras de entender y hacer grabado. La primera visión lo concibe como el desarrollo de una habilidad, de una técnica cuya utilidad radica en poder reproducir imágenes prediseñadas. La segunda acepción por el contrario, lo aborda como un lenguaje artístico, con una auténtica sintaxis de la forma, donde se genera las propias condiciones expresivas que forma, do se genera las propias condiciones expresivas que surgen del pensamiento divergente. El grabado creativo presenta determinadas cualidades físicas y sensoriales, las cuales nos remiten a un proceso dibujístico complejo, abierto a las vicisitudes propias del material que se transforma empleando nuestras manos, nuestro cuerpo para explorar, para conocer.

There are two ways of comprehending and making engraving. The first vision understands it as the development of a skill or of a technology, which usefulne nology, which usefulness is based on being able to reproduce pre

Palabras clave: Grabado, dibujo, proceso divergente sensorialidad, fluidez Key words: Engraving, Drawing, Divergent Process, Sensory qualities Fluency defines engraving as an artistic languege, as an authentic syntex defines engraving as an artistic language, as an authentic syntax of the form, where the own expressive conditions that arise from the divergent thought are generated. Creative engraving exposes certain physical and sensory qualities, which refers us to a complex drawing process, opened to the personal experiences of the matter being transformed, using our own hands and our own body to explore, to know.

\section{Antecedentes}

Nuestro propósito al escribir este artículo es el de ponderar y dar visibilidad al proceso de creación de una imagen a través del lenguaje del grabado calcográfico.

¿Por qué dar más importancia a un proceso que al resultado? Estamos impregnados de un sentido de finitud en todo lo que hacemos. Estamos obsesionados por el acabado de las imágenes sean o no naturalistas. El entorno en que nos desenvolvemos favorece esta situación porque jerarquiza como sea y ante todo, la obtención de un resultado específico, previsto y acabado.

Esta obcecación por el resultado nos encamina a trabajar como autómatas, con la vista y la cabeza centradas en conseguir los objetivos propuestos. Pero, ¿Cómo se traducen esos objetivos concretos en la estampa? Se encuentra muy enraizada la idea de que no podemos abordar ningún proyecto o propuesta seria, sin tener muy claro cómo sería el resultado final. Los bocetos o dibujos preparatorios conducen a asumir la previsión de la imagen. Pues bien, desde nuestro punto de vista, esta actitud cercena el desarrollo de un sinfín de posibilidades que se generan casi por sí solas, gracias al grado de flexibilidad perceptiva y actitudinal que ejerzamos cuando se talla una plancha. Por lo tanto, el trabajo que debe preocuparnos no es el que desarrollemos a modo de boceto previamente sobre un papel, sino el que se desenvuelve directamente sobre la matriz con la punta de acero y el rascador.

Creo que puede afirmarse, en general, que el gran artista sólo ha utilizado habialmente procedimientos gráficos cuando eran relativamente directos, y que el deseo tualmente procedimientos graficos cuando eran relativamente directos, y que el deseo de expresion es incompatible con los metodos indirectos, con la complejidad técnicay

Es evidente entonces, que entre más filtros utilicemos para expresarnos a través de las imágenes, más alejados nos encontraremos de las complejas esencias perceptuales que nos brindan todos nuestros sentidos al unísono. Las artes en general y en particular el grabado nos invitan a prestar atención a esas cualidades sensoriales para poder experimentarlas plenamente, para no conformarnos únicamente con un reconocimiento superficial de las formas". (EISNER, Eliot: 2004; 22)²

Por otra parte, la demanda de productos novedosos en todos los

TIVNIS, W. M.: Imagen impresa y conocimiento. Análisis de la imagen prefotográfica, 1975, pp. 225 2 "Dewey distingue entre percepción y reconocimiento. La precepción exige exploración. reconocimiento tiene lugar cuando lo percibido recibe una etiqueta y es objeto de discusión. Véase su obra Art as Experience, Nueva York, Minton Balch, 1934. Citado por EISNER, ELLIOT. W. El arte y la creación de la mente, 2004, pp. 296 ámbitos, propicia la búsqueda obsesionada de efectos inmediatos que causen gran impacto visual; esta obcecación por la apariencia, por la imitación, se vio reflejada también en la manera en que evolucionó técnicamente el grabado a partir del siglo XVI hasta el descubrimiento de la fotografía, donde el único objetivo era la reproducción fiel de imágenes ajenas a la propia sintaxis del grabado, en buena parte, carentes de fundamento plástico o creativo; precisamente porque cuando existe un camino tan definido entre el referente y la forma representada, no existe margen para la indagación porque todo el trabajo se encorseta en elementos predeterminados. Por otra parte, el grabador perceptivo, sensibiliza con su actitud y sus manos el medio para que éste sea propicio para la expresión. 
Es justamente esta condición, lo que diferencia al grabado para un fin utilitario o como un ejercicio de transformación en sí mismo. Desde esta perspectiva, el sentido interesado del grabado queda obsoleto y desprestigiado porque esconde su verdadero potencial: el de abrirnos a la percepción de lo que se pude hacery no de lo que se quiere hacer.

Por ello me parece significativo intentar desentrañar algunos tópicos sobre la imagen impresa artesanal (hago hincapié en el término artesanía porque no quiero utilizar el neologismo de "analógico" para referirme a un concepto primordial que implicaría la interacción de nosotros mismos y con el mundo a través de nuestros sentidos, principalmente el del tacto). Parto por consiguiente, de nuestra propia experiencia en esta disciplina artística, para deducir que hay dos maneras de abordar el grabado, tanto desde su práctica como desde su precepción

\section{Las dos visiones del grabado}

Para poder comprender la importancia que tiene el proceso creativo en el grabado, hemos establecido una hipotética confrontación entre las dos maneras que prevalecen cuando se aborda la gráfica desde su práctica. Denominaremos de aquí en adelante la primera visión con la letra $A$ y la segunda con la letra $B$.

La primera visión (A) es más racional que sensorial y afronta el grabado como una técnica de impresión, cuya finalidad es la reproducción de imágenes originales a partir de un boceto o un referente muy premeditado o perfectamente establecido. Los cambios en la plancha no tienen mayor relevancia siempre y cuando no afecten el sentido estricto de la imagen final. Esta circunstancia evidente, es heredera de la supeditación que ha tenido el grabado a imitar y reproducir infinidad de veces, a lo largo de toda su historia, otro tipo de imágenes pictóricas o dibujísticas terminadas. Los artistas que rompieron con esta inercia fueron desde luego los que trascendieron este sentido univoco del lenguaje gráfico para convertirse en referentes como creadores dentro del concepto moderno de grabado. Son ellos precisamente los que llenan con sus obras todos los libros monográficos. Pero que sin embargo, desconocemos cuál es la esencia artística de sus estampas. Personalmente me gustaría resaltar a Durero, en el S. XVI; Rembrandt en el S. XVII y Goya S. XVIII. A finales del S. XIX la tendencia cambia gracias a los artistas expresionistas.

Todas las técnicas que surgían lo hacían por un afán de imitar: la manera negra para imitar la pintura al óleo; el pointillé para imitar los dibujos coloreados a la aguada; las ruletas se introdujeron para trazar lineas rigurosas con las de la tiza; el aguatinta se desarrolló para imitar la aguada de tinta china o las acuarelas; el barniz blando para imitar los dibujos a lápiz $z^{3}$

Por lo tanto, su objetivo no es otro que el de trasladar lo más fiel C DUPLESIS, J.. Las maravilas del grabado. París 1873 pp. 328-331. Citado por SÁEZ DEL ÁLAMO, C. El grabado en color por zieglerogra
fiá, p.19. Bilbao, 1989 osible la expectativa, esa idea previa a la plancha. Aquí no importa el cómo, sino el qué. Es decir, lo verdaderamente sustancial es el efecto final más que el proceso.

La segunda acepción (B) por el contrario, concibe al grabado como un recorrido sensible que nos invita a descubrir, a profundizar en el abismo de lo desconocido, porque una estampa al igual que un dibujo, "revelan más claramente su proceso de ejecución" (Berger: 2011; 56), cuando logramos captar sus cualidades matéricas y sensoriales durante el transcurso de su propia elaboración. La acción de tallar desarrolla y promueve todos los estadios de tras-formación que están implícitos en todo proceso artístico.

La naturaleza del grabado favorece que aparezcan factores o circunstancias azarosas o inesperadas que son difíciles de controlar; $Y$ eso es precisamente lo que le diferencia de otros procedimientos no dibujísticos: aquí más que en ningún otro lenguaje, el error hay que asumirlo como una parte sustancial de un proceso creativo y no como una equivocación que se intenta desechar, ocultar y olvidar sin más.

Un gran estudioso del dibujo como lo es John Berger nos acerca a esa actitud que debemos de asumir hacia la incertidumbre que surge cuando estamos ante un soporte con las herramientas en la mano:

Tengo el presentimiento de que el dibujo es una actividad manual cuyo objetivo es abolir el principio de la Desaparicion. (O, para decirlo con otras palabras, transformar las apariciones y desapariciones en un juego más serio que la vida)... Dibujar es un proceso continuo de corrección. Es un proceso que avanza corrigiendo errores ${ }^{4}$.

Justamente porque la visión (A) del grabado tiene un objetivo específico que seguir, el error es la equivocación que le desvía de la consecución de su claro objetivo. Por lo que hay que ocultarlo o eliminarlo cuanto antes.

La diferencia de la visión A con la B es que la segunda, asume las herramientas como extensiones de los sentidos. No se pelea con ellas porque perdamos su control sobre nuestras expectativas, se asumen como parte de la acción que conduce a la expresión. Es decir, que se fusiona con todas esas cualidades físicas y sensoriales del medio para desarrollar con ello un proceso dibujístico abierto al devenir y las vicisitudes del propio material. Para transformar con los atributos de las herramientas, del soporte y de la mano, la propia actitud hacia ellas, mediante un diálogo fluido y flexible.

Shitao, a quien vuelvo citar, escribió lo siguiente; "Pintar es el resultado de a receptividad de la tinta; la tinta se abre al pincel; el pincel se abre a la mano; la mano se abre al corazón. Y todos ellos de la misma forma en que el cielo engendra lo que la tierra produce: todo es el resultado de la receptividad ${ }^{5}$.

Trasladando las bellas palabras de Shitao al grabado podríamos decir que grabar es el resultado de la receptividad del soporte, de la plancha; la plancha se abre a la punta o al rascador; la punta de acero y el rascador se abren a la mano; y la mano se abre al corazón, y se cierra a nuestros ojos y a nuestra mente.

Resumiendo, la visión A utiliza el procedimiento para un determi-

4 BERGER, J.: Sobre el dibujo Barcelona, 2011, p. 97 5 BERGER, J.: Algunos pasos hacia una pequeña teoría de lo visible,
Madrid, 1997, p. 46 nado fin. La visión B en cambio, se fusiona con el medio para indagar y descubrir otras vías de experiencia gráfica. El resultado final del primero es el grabado decorativo; mientras que la del segundo; es la expresión sin cortapisas, es el grabado de creación. 
Desde nuestra perspectiva, consideramos que ambas visiones están patentes en todos los procesos de la talla y que depende de la percepción y de la actitud del propio grabador que prevalezca uno u otro. No obstante, cuando nos acercamos a la receptividad de la segunda visión del grabado, es sin lugar a dudas cuando el proceso se vuelve más fluido, divertido, energético y creativo.

\section{La temática no es la finalidad, sino únicamente un comienzo. el} dibujo como fortaleza

Para poder reflexionar sobre esta problemática, hemos querido tomar como referencia principal el último trabajo en el que estamos sumergidos. Se trata de seis ilustraciones basadas en sueños de niños mexicanos. Un encargo de Roger Omar para su proyecto El monstruo de colores no tiene boca. Los textos que elegimos son sucintos y la mayoría se refieren a seres o situaciones insólitas que son fácilmente traducibles a lo visual. Pero precisamente esta facilidad de narración era la que tenía que evitar en mis imágenes. Es decir, la literalidad. ${ }^{6}$

Nunca antes habíamos hecho una ilustración con grabado calcográfico. Por lo tanto, este encargo se nos presentaba como una buena oportunidad para corroborar que la imagen, pese a su temática o referencia, tiene siempre un recorrido muy amplio y divergente; siempre y cuando por supuesto, abandone el sentido de finitud y certeza que la encadena a la expectativa de un resultado específico. Sin embargo, nos motivaba la idea de comprobar hasta dónde podrí llegar una imagen que se desarrollaría con un proceso antitético al que suele usarse en la ilustración: el grabado calcográfico. Antípoda en esencia a las herramientas digitales, sencillamente porque los procesos del grabado son contundentemente procesuales y artesanales y requieren además de un transcurso de maduración pausado y reflexivo hasta que la propia imagen nos desvele que no puede ir más allá de sus propias posibilidades.

La idea original de este proyecto se desarrolla como un políptico, o más bien como una imagen única que mide $21 \times 100 \mathrm{~cm}$. Por consiguiente, uno de los principales problemas que teníamos que resolver era de carácter técnico o de infraestructura, al no tener la posibilidad de morder una plancha tan grande en el taller para abarcar los cinco sueños a la vez, tuvimos que dividir la imagen en dos partes. Por un lado, teníamos una plancha de 21 x $40 \mathrm{~cm}$. abarcando dos sueños. Y por el otro, la segunda placa de $21 \times 60$ $\mathrm{cm}$. que haría referencia a tres textos. De esta manera, nos sería menos complicado poder tallar amabas matrices por etapas y registrar al mismo tiempo, todos los estados intermedios sin ninguna dificultad.

La segunda problemática inicial a solucionar sería la interpretación de un texto más o menos narrativo al lenguaje visual de las imágenes. Los textos fueron escritos por niños de ocho años, lo que les otorga un carácter algo etéreo, poco definido en sentido de significado y abierto en consecuencia a infinidad de variantes plásticas. Esta circunstancia

fueron las que en parte nos motivaron para asumir este trabajo.
Comenzamos el proyecto con la plancha de $21 \times 20 \mathrm{~cm}$. que contiene la única imagen suelta del acordeón; es la portada: El gato truenapies $^{7}$. Aparentemente el texto era un poco repetitivo y descriptivo, pero al mismo tiempo sugerente y cargado de fantasía, lo que atrajo inmediatamente nuestra atención para tomarlo como pretexto para comenzar a dibujar.

En sentido estricto, no nos motiva realizar bocetos o dibujos previos de un tema que debemos que resolver con otro lenguaje. Definitivamente preferimos abordar la imagen directamente sobre la plancha para no estar condicionados por el referente o el motivo desde el inicio. Con la xilografía no hay problema porque su propia sintaxis, te obliga a sintetizar y a adaptarte casi sin problemas al lenguaje directo y contundente que genera la madera. Sin embargo, con el grabado en hueco no sucede lo mismo. La rigurosidad del procedimiento calcográfico, te obliga de alguna manera, a seguir unas pautas muy específicas que conllevan a un mayor detenimiento y a un estado más reflexivo y consciente del proceso. Esto se debe a que el dibujo lineal en el grabado en hueco se desarrolla con unas herramientas muy finas que consecuentemente tienden a un trabajo más minucioso. De esta forma, la tendencia se inclina hacia el detalle, pero precisamente por ello, se requiere un cambio de actitud que sea contundente para romper con esta inercia que nos impide disfrutar de un lenguaje más fluido y espontáneo sobre la plancha de metal.

Cabe resaltar aquí que la búsqueda de combinaciones entre diferentes lenguajes del grabado con el fin de encontrar una 'resurrección' de la gráfica, centrada mayoritariamente en 'innovaciones técnicas' realizada por los artistas que se encuentran situados en la visión A del grabado, ha desvirtuado el fundamento de la investigación en esta disciplina artística. Evidenciando nuevamente, que lo que realmente preocupa a muchos grabadores contemporáneos, al igual que pasaba desde el siglo XVII, son los resultados aparentes de algunos recursos de estampación y no la gran problemática que implica el cómo evoluciona y se crea la imagen gráfica directamente en el soporte de la talla.
7 " Hoy soñé que en la noche me pies. Yo moví los pies y no había nada... Y todavía me andaban tronaba pies. Lo vi y se fue volando". Texto de An. Lovi y se fue volando". años deztotio, Miño de ocho años, Mazatlán, México, 2004
8. SAEZZ DEL ALAMO, C.: op.cit andaban tronando los dedos de los

El enfoque de la investigación donde se falla, ya que intenta buscar soluciones a través de recursos de estampación, cuando en realidad lo verdaderamente importante y problematico dentro de la estetica actual viene en el momento mis de crear una imagen, no en el hecho de imprimirla. impronta, espontaneidady valentla en la creación son premisas que el artista antepone a cualquier resultado posterior de estampación, y esas premisas sin medios directos capaces de llevarlas a cabo, son imposible de plantearse ${ }^{8}$.

¿Cuáles son entonces esas destrezas y habilidades complejas que debemos desarrollar para acercarnos más a ese estado de indagación de la imagen gráfica? Es el dibujo sin lugar a dudas, el medio que nos acercará a la verdadera naturaleza de la imagen; desarrollará en nosotros la capacidad de proximidad a un estado perceptivo acrecentado para asimilar la realidad sensitivamente a través de la acción de nuestro propio cuerpo al trazar y no tanto por nuestro sentido de la

\begin{abstract}
gallina en el mar y la sacamos. Ten regresamos" (Eduardo, 2004)

"Yo soñé que vino un circo y luego sangrado y al final mi amigo ya que tenía ocho manos y cuatro pies salir" (Monse, 2008); "Soñé que y nos comían, y de repente me
\end{abstract}


vista. Al parecer todas estas acciones físicas, nos obliga a cambiar toda nuestra capacidad perceptiva con el fin de erradicar los tópicos de la visión. El grabado tiene cualidades táctiles muy acentuadas que nos trasladan inmediatamente a vislumbrar intuitivamente una realidad que se está creando gracias al diálogo íntimo entre el artista-artesano y su medio de expresión, únicamente mediante sus manos. Pero no como una herramienta de la cabeza sino como una extensión del corazón, de todos nuestros sentidos.

Como decíamos anteriormente; realizar un boceto para calcarlo posteriormente a la plancha, no es un método que solemos seguir. $\mathrm{Si}$ queremos romper con la certeza ¿Cómo podríamos marcarnos desde antes del inicio el camino a recorrer? En su lugar, procuramos dibujar con asiduidad. A ser posible todos los días; ello me permite tener fluidez a la hora de abordar la resolución de cualquier imagen sin detenernos precisamente en el referente, en el detalle anecdótico de la parte. La práctica del dibujo sin un fin representativo, ayuda a abrir el espacio como un todo, percibido como un conjunto unificado de una manera orgánica y simultánea.

Posiblemente nos decantamos por ese sueño del gato para iniciar el políptico, porque llevamos algunos años dibujando al nuestro. Es el único modelo que tenemos a mano de manera incondicional. Aún así, no ha sido el hecho de tener muchos referentes de este animal lo que ha dispuesto que comenzara precisamente por esta imagen del sueño. Por lo que deducimos que dibujar a 'Coco', ha sido la única manera de interiorizar la forma sin tener que mimetizarla. Todo ello gracias a un recorrido perceptivo constante que se manifiesta quizás por perder el miedo a dibujar, para desechar también los tópicos como el parecido, o el acabado basado en el claroscuro o la ofuscación por la proporción. Todo ello nos ayudó a transformar la conmoción de la frustración por la supuesta perfección, a la feliz sensación de fluidez que provoca el estado de receptividad con todo lo que nos rodeaba.

¿No es el acto de dibujar, así como el dibujo en sí mismo, más devenir que ser? ¿No es un dibujo lo opuesto a una fotografía? Las fotografías detienen el tiempo, lo capturan: mientras que los dibujos fluyen en él. ¿Podríamos decir que los dibujos son torbellinos en la superficie de la corriente del tiempo? Utilizabas la idea de la corriente eléctrica, pero ya se trate de la electricidad o del agua siempre es un flujo. $Y$ dejarse arrastrar por la corriente significa abstraerse ... transportarse $e^{9}$

\section{La batalla entre la incertidumbre del devenir y la certeza de}

\section{la finitud}

Siguiendo el procedimiento de nuestros anteriores grabados, procedemos a barnizar la plancha para después dibujar sobre ella con la punta seca para posteriormente morderla en el ácido nítrico (aguafuerte). Digamos que este es un procedimiento que destaca las cualidades del dibujo lineal. En nuestro caso nos ayuda a establecer una estructura simultánea entre la imagen y el fondo, además de facilitar los trazos Fig. 1 Gato truena pies. $1^{\text {a }}$ prueba
de estado. Aguafuerte/plancha de zinc, 2015

Fig. 2 Gato truena pies. $11^{\text {a }}$ prueba definitiva. Aguafuerte, punta seca raedor/plancha de zinc, 2015

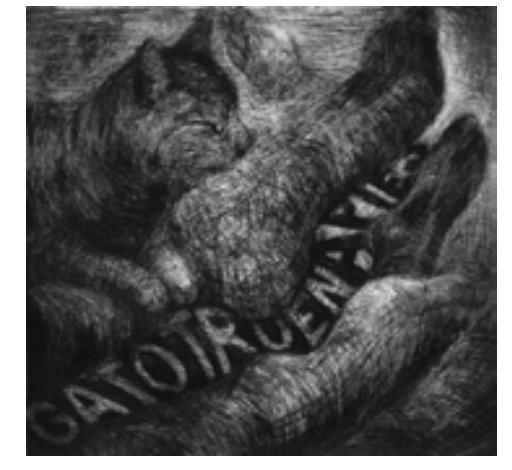

no solamente por sus contornos, como si de una malla o red orgánica se tratase. El aguafuerte por otro lado, nos ayuda a establecer rápidamente la idea primaria sobre la plancha; equivalente a colocar la primera piedra de la construcción. No obstante, en esta primera imagen del acordeón de los sueños, se evidencia un inicio más riguroso, menos fluido quizás; porque es muy probable que sea esta plancha donde haya menos variantes en el proceso de los doce estados del grabado. Se evidencia por consiguiente, que al no haber elaboración previa, se pierda la fluidez que evita centrarse en detalles específicos que pensábamos eran imprescindibles para la unión con el texto: el gato y los pies por ejemplo. Y aunque conscientemente pretendemos mostrar una imagen que no sea narrativa, caemos nuevamente en la inercia del referente, de lo nombrado, de lo reconocible. ¿Por qué este apego al referente obstaculiza un desenvolvimiento fluido? (Fig. 1 y 2)

En el grabado existen dos condiciones que hay que tener en cuenta para acercarnos a la veracidad gráfica. En primer lugar asumi que las figuras o las formas no se encuentran flotando en el espacio. Es decir, que la relación entre el fondo y la figura, es más acentuada en el grabado que en el dibujo sobre papel. Aunque no obstante, esta problemática está presente naturalmente también en la pintura, es en el grabado donde más se resalta. Sencillamente porque la asunción del espacio gráfico, implica asumir como elementos activos los cuatro lados de la plancha y no solamente la base de la tierra o del horizonte ilusorio del concepto euclidiano. En el espacio gráfico no existe la gravedad real, sino la tensión provocada por la igualdad de condiciones de los bordes superior, inferior y laterales. Ahora bien, cómo se consigue esa tensión de la que hablamos. Con otra cualidad del grabado; el contraste. En sentido estricto es el juego o la interacción armónica entre el blanco y el negro. Es decir entre los espacios $y$ las formas positivas y negativas.

Por otra parte, es necesario trascender el referente en el transcurso del proceso. Si lo conseguimos dejar atrás, es muy probable que experimentemos un estado acrecentado de la percepción, donde las expectativas, ideas preconcebidas y los tópicos visuales pierden relevancia para diluirse en el devenir de la imagen transgredida, incidida, raspada, arañada, bruñida. Es decir, de la imagen grabada. 
Fig. 3. Yo vivía en un árbol y Vino
un circo, 1er estado, aguafuerte/ un circo, ler estado, ag
zinc, $21 \times 40 \mathrm{~cm}, 2015$

Fig. 4. Yo vivía en un árbol y Vino un circo, $2^{\circ}$ estado, aguafuerte, punta seca y raedor/zinc, $21 \times 40$ $\mathrm{cm}, 2015$

Fig. 5. Yo vivía en un árboly Vino un circo, $6^{\circ}$ estado aguafuerte, punta
seca y raedor/zinc, $21 \times 40 \mathrm{~cm}, 2015$

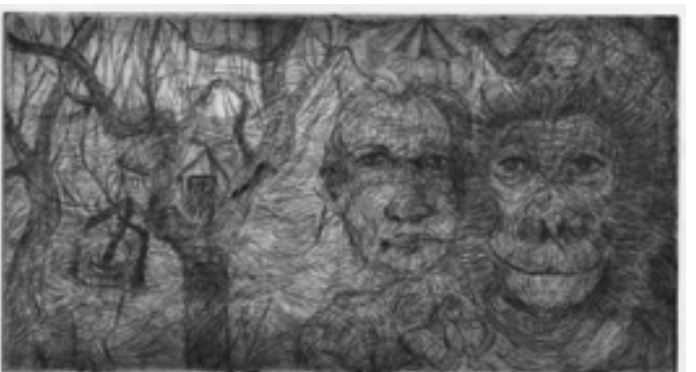

La segunda plancha que incluía dos imágenes unidas; El chango y la casa en el árbol, tuvo más o menos el mismo recorrido que la primera. Nuevamente nuestros referentes para la composición fueron nuestros anteriores dibujos hechos con rotulador o bolígrafo. Digamos que gracias al tratamiento nítido de la línea con estas herramientas de dibujo, los personajes principales se vislumbraban de una forma mejor estructurada para su posterior deconstrucción con el aguafuerte en la matriz de zinc. No obstante, la distribución de las figuras en el grabado, implica siempre su unión con el contexto global del espacio. Es decir, que aunque tuviésemos una imagen genial y la dibujáramos en el centro de la plancha, no tendría ningún interés porque se encontraría aislada, totalmente desvinculada de su espacio circundante. Por lo tanto, recurrimos nuevamente el dibujo de construcción intrínseca10 con el fin de relacionar simultáneamente y sin diferenciar, todas las formas que aparecen en la plancha con una misma acción de trazado. Este procedimiento propicia a trabajar todo el espacio de una manera fluida, sin discriminar entre el fondo y la figura. De esta manera, se impide definir las figuras por su contorno, para evitar crear formas cerradas que dificultarían su conexión con las contiguas. Las líneas aunque en apariencia se visualicen como caóticas, responden a un sentido táctil debido a su trazado convexo o cóncavo, además de por su intensidad. En este caso, es la saturación de todas ellas la que nos otorga la densidad a la forma, precisamente desde su interior, desde su esencia. Entre mayor saturación, la imagen es más sólida.

En esta imagen se puede apreciar perfectamente cómo la variedad de línea ayuda a establecer una concordancia con el espacio vacío. Es decir con aquél que se denominaría 'fondo'. Nótese como el tratamiento de trazo es muy similar entre las figuras y el espacio que les circunda. No existe la jerarquización de la forma sobre el fondo. Tampoco podremos encontrar tratamiento de contorno para definir las formas; los trazos intentan ser vinculantes. Las figuras se definen por las calidades de su superficie, así es en la parte de los troncos de los árboles dónde más se ha insistido con la punta, ello no quiere decir que los troncos sean negros, sino que debido al tacto rugoso de su corteza nos remite a la insistencia del trazo. Aquí el sentido de claroscuro se desvanece para dar paso al intercambio de zonas positivas o negativas, sin apegarse al sentido estricto de la luz y la sombra, ya que esta circunstancia puede cambiar indistintamente entre una zona u otra en el transcurso del proceso (Fig. 3).
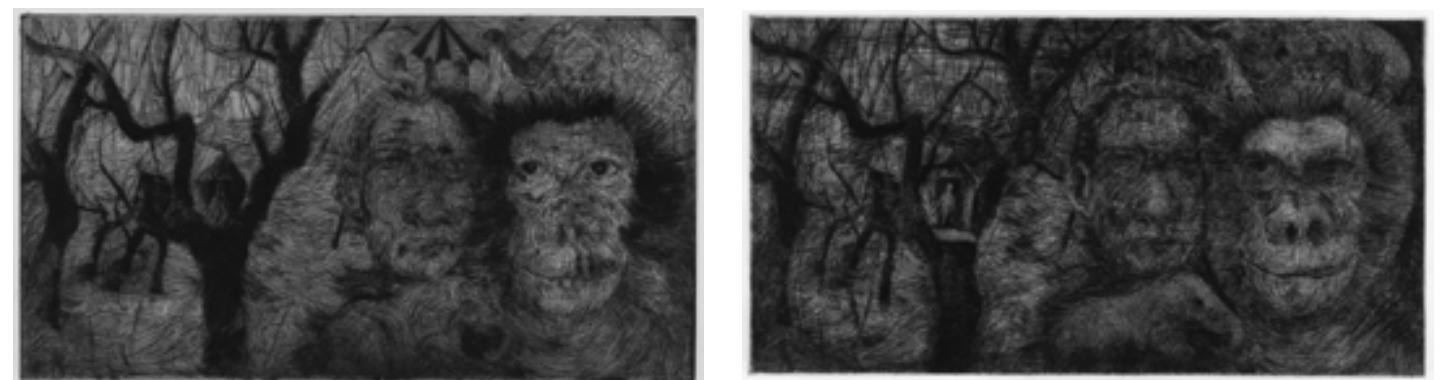

A partir del segundo estado comienza el trabajo con la punta seca y el rascador. La punta seca tiende a conseguir áreas negras casi de manera inmediata; por lo que su tendencia natural es la de saturar las zonas que consideramos profundas u oscuras como pueden ser el pelo y los ojos del mono, la pared lateral de la casita en el árbol y los troncos también. Sin embargo, se aprecia tímidamente cómo hay algunas zonas en que su aplicación no es naturalista, y busca muy sutilmente valorar espacios positivos con negativos. Por ejemplo, el toldo de la carpa del circo, la zona detrás del elefante de la parte inferior y también para ayudar a redefinir el trazo realizado con el aguafuerte como se evidencia en la trompa del segundo elefante en la parte superior (Fig. 4).

Hasta el sexto estado del grabado la talla fue directa con la punta

seca y en menos intensidad con el rascador. La imagen tiende ahora a oscurecerse porque los trazos de la punta se reparten por todo el espacio y no solamente por las zonas profundas u oscuras. En este estado no se trata de buscar el contraste inmediato en la composición, sino redibujar y redefinir también aquellas formas que se apreciaban de una forma ambigua. Es el caso de la cara del niño en la parte central derecha, así como también todo el espacio entre las figuras. Se traza variando la dirección y también la intensidad de la línea. (Véase toda la zona superior de la plancha, donde empieza a ser complicado distinguir entre fondo y figura). Por otra parte también utilizamos el rascador para dibujar por sustracción. Es decir por trazos negativos. Definitivamente disfrutamos mucho de esta etapa porque se trabaja de una manera directa que no admite términos medios, es un proceso que remite de alguna manera a la xilografía porque infringimos toda nuestra fuerza en rascar la plancha para rebajar la línea del aguafuerte. Lo anterior se puede corroborar muy bien en la cara del mono, en la figura de la casita del árbol y en el elefante de la parte inferior (Fig. 5)

El siguiente estado, el número siete puede apreciarse que empieza a aclararse la imagen. Es decir, comenzamos a invertir la tendencia inicial a oscurecer todo el espacio. El trabajo con el rascador es predominante; a tal grado que parece que ha pasado de la noche al día. Pero no fue ese nuestro propósito. Buscábamos únicamente dejar hablar los trazos profundos realizados con el aguafuerte y la punta seca en primeros estadios de la estampa. Al mismo tiempo empezábamos a establecer el juego gráfico del blanco y negro (Fig . 6) 

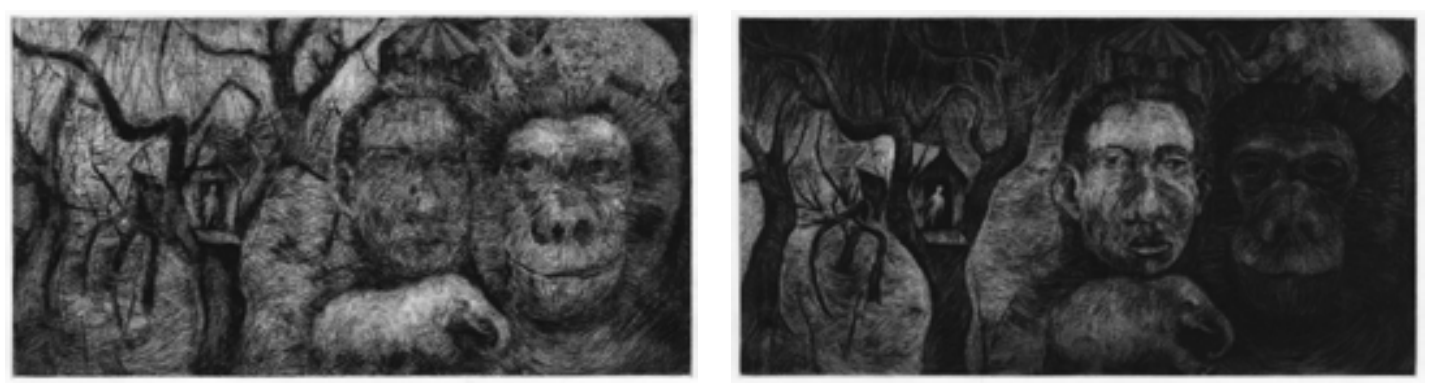

Fig. 6. Yo vivía en un árboly Vino un circo, $7^{\circ}$ estado aguafuerte, punta seca y raedor/zinc, $21 \times 40$ $\mathrm{cm}, 2015$

Fig. 7. Yo vivía en un árboly Vino un circo, $10^{\circ}$ estado aguafuerte,
punta seca y raedor/zinc, $21 \times 40$ punta seca
$\mathrm{cm}, 2015$

Fig. 8. Yo vivía en un árboly Vino un circo, $15^{\circ}$ estado definitivo aguafuerte, punta seca y raedor/zinc, 2 $\times 40 \mathrm{~cm}, 2015$
En el estado número diez, resinamos la plancha para aplicarle un tono negro general a la plancha. Equivaldría a tachar un dibujo que no nos satisface. El motivo principal de esta decisión no fue otra que conseguir un negro más intenso para seguir trabajando por sustracción por medio del rascador. Volvemos a modelar la cara del niño, la del mono más sutilmente porque deseamos que contraste en tonalidad con la primera. También el espacio circundante de la parte inferior izquierda se redibuja otra vez con trazos negativos (Fig. 7). La materia que nunca mejor dicho, otorga corporeidad a nuestros pensamientos con la finalidad de que éstos fluyan a través de nuestro tacto hacia el soporte y viceversa. De esta manera, son nuestras manos, los impulsos y sensaciones del cuerpo al realizar los trazos con herramientas metálicas y su repercusión sobre un soporte también metálico, los que nos hablan. Todas estas experiencias táctiles, kinestésicas y propioceptivas, son las que nos acercan plenamente a nuestra consciencia corporal, aquella que nos hace percibir sensorialmente sin interferencias racionales. Juhani Pallasmaa clarifica esta problemática al afirmar que:

Estamos conectados con nuestro mundo a través de nuestros sentidos; estos no son simples receptores pasivos de estímulos, ni el cuerpo es únicamente un punto para ver el mundo desde una perspectiva central. La cabeza tampoco es el único lugar de pensamiento cognitivo, pues nuestros sentidos y todo nuestro ser corporal estructuran, producen y almacenan directamente un conocimiento existencial silencioso. El cuerpo humano es una entidad cognitiva. Todo nuestro ser en el mundo es un modo de ser sensorial y corporal ${ }^{1}$

\section{Conclusiones}

Exponemos a continuación los aspectos que consideramos más relevantes de esta breve explicación:

- Trabajar desde la incertidumbre

- La búsqueda de una certeza desde el inicio del proceso, nos costa la quimérica perfección.

- El grabado es el medio idóneo para desapegarse del resultado previsto. Por la naturaleza de sus soportes, nos permiten una indagación casi infinita en base al ensayo y error; ese acierto, si se puede llamar así, es el resultado de infinidad de rectificacondicionará a trabajar como autómatas, para buscar a toda
Alejandro Rodríguez León

(México D.E 1961) Licenciado en fica por la Escuela Nacional de Artes Plásticas/ UNAM. Beca predoctor otorgada por concurso por la Secretaría de Relaciones Exteriores del Gobierno Mexicano y el DAAD Aleman para estancia investigadora en la Hochschule fúr Bildende Künste en la ciudad de Braunschweig. Beca Fonca/ México para tesis doctoral. Profesor Contratado Doctor en el Departamento de Dibuio/ Facultad de BBAA y miembro del grupo de Investigación Arte y Entorno de la Universidad Politécnica de Valencia. Dibujante, grabador y hacedor de libros de artista.

\section{Bibliografía}

BERGER, JOHN: Algunos pasos hacia una pequena teoría de lo 1997,64 pp 997, $64 \mathrm{pp}$ Barcelona, Ediciones Gustavo Gil $2011,152 \mathrm{pp}$

ELLIOT, W. EISNER: El arte y la creación de la mente. El papel de las artes visuales en la transformación de la conciencia, Barcelona, Ed. Paidós, 2004, 318 pp. IVINS, W. M.: Imagen impresa y prefotográfica. Anarcelis de la imagen Gustavo Gili. 1975, 268 pp ORDINE, NUCCIO: La utilidad de Io inútil. Manifiesto, Barcelona, Editorial Acantilado, 2013, $176 \mathrm{pp}$. PALLASMAA, JUHANI: La mano que piensa. Sabiduria existencial y CoF poral en la arquitectura, Barcelona, Editorial Gustavo Gilli, 2012, 386 pp SAEZ DEL ALAMO, Mª CONCEPCION: El grabado en color por zie-

1989, 160 pp.

Francisco de Goya (1746-1828) Edward Munch (1863-1944) Ernst Ludwig Kirchner (1880-1938 Max Beckman (1884-1950) José C. Orozco (1883-1949) James Ensor (1860-1949) Francisco Toledo (1940-) Markus Luperz (1941-) Mimo Paladino (1948)

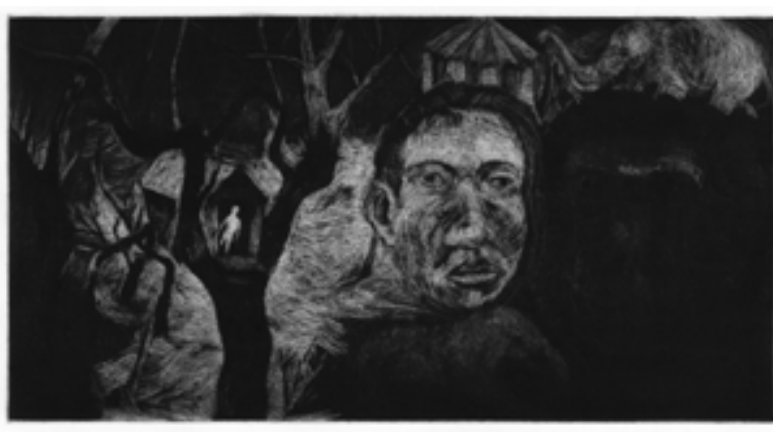

ciones y titubeos, que finalmente nos permiten desapegarnos de una idea fija y concreta de forma. El proceso nos ayuda a percatarnos de ese camino, donde la huella es la clara evidencia de esa lucha entre el querer y el poder.

- El dibujo sensible de construcción intrínseca, nos permite un ejercicio pleno de libertad en la configuración de la imagen sobre la plancha. Perdemos el miedo a equivocarnos porque fluimos con mayor facilidad. La equivocación es justamente la catapulta para romper con nuestras expectativas.

- El uso de la punta seca alternado con el rascador, nos permite asumir una situación inusual, en donde la convicción del trazo positivo y del negativo, alternando la dualidad del blanco y el negro, ya no como un elemento descriptivo de la luz y la sombra, del claroscuro, sino como un elemento real de hapticidad y sentido de la tactilidad mediante gesto propio al dibujar; el trazo expresivo en la dialéctica de fuerzas entre el lleno y el vacío.

\section{Diferencias entre el concepto de claroscuro y la forma negativa y}

\section{positiva.}

La gran diferencia entre la visión academicista o convergente del claroscuro en comparación con el concepto de positivo y negativo o sentido gráfico del espacio, radica fundamentalmente en que el primero concibe y organiza el espacio en base a la luz y a la sombra en un sentido plenamente naturalista. Desde una perspectiva netamente plástica o gráfica, la luz es la ausencia de forma, de percepción táctil o percepción de superficie. Por otro lado, se entiende la sombra como la saturación de un área determinada de cualquier manera. En su disposición no se comprende o asimila la forma que hay debajo de esa zona en penumbra. Lo que ocasiona que esas zonas queden inertes 0 desconectadas del resto del espacio.

El blanco o elemento negativo tiene exactamente la misma importancia que el positivo o negro; en el espacio gráfico no hablamos de reserva en el dibujo, sino por el contrario de una forma en negativo, una forma con intención de trazo, pero que es blanca o negativa. Lo que propicia una íntima y continua relación dialéctica entre el lleno y el vacío. (Fig. 8) 